\title{
CONSTRUÇÃO E IMPLEMENTAÇÃO DE UM HORTO MEDICINAL: UM PROJETO DE EXTENSÃO UNIVERSITÁRIA
}

\section{Construction and implementation of a medicinal garden: a university extension project}

\section{Construcción e implementación de un huerto medicinal: un proyecto de extensión universitaria}

\author{
Marcio Rossato Badke (iD \\ Universidade Federal de Santa Maria - UFSM - Santa Maria (RS) - Brasil \\ Daiana Cristina Wickert iD \\ Universidade Federal de Santa Maria - UFSM - Santa Maria (RS) - Brasil \\ Gabriela Oliveira iD \\ Universidade Federal de Santa Maria - UFSM - Santa Maria (RS) - Brasil \\ Jordana Lima da Silva iD \\ Universidade Federal de Santa Maria - UFSM - Santa Maria (RS) - Brasil \\ Hentielle Feksa Lima iD \\ Universidade Federal de Santa Maria - UFSM - Santa Maria (RS) - Brasil \\ Maria Denise Schimith (iD \\ Universidade Federal de Santa Maria - UFSM - Santa Maria (RS) - Brasil \\ Laís Mara Caetano da Silva iD \\ Universidade Federal de Santa Maria - UFSM - Santa Maria (RS) - Brasil \\ Silvana Bastos Cogo iD \\ Universidade Federal de Santa Maria - UFSM - Santa Maria (RS) - Brasil
}

\section{RESUMO}

Objetivo: Relatar a experiência no processo de construção e implementação de um horto medicinal para a manutenção e o cuidado à saúde de uma comunidade. Síntese dos dados: Tratou-se de um relato de experiência oriundo do desenvolvimento de um projeto de extensão universitária intitulado "Espaço de aprendizagem - relógio medicinal do corpo humano", desenvolvido no bairro de um município da região central do estado do Rio Grande do Sul, Brasil. Participaram do projeto integrantes da comunidade, profissionais das áreas de Enfermagem, Biologia, Agronomia e Paisagismo, acadêmicos de Enfermagem, estudantes de ensino médio e bolsistas estudantes de uma instituição de ensino superior. As atividades foram realizadas nos meses de abril a dezembro dos anos de 2017 e 2018. O relógio foi desenvolvido em um território público da comunidade, constituído por 26 plantas medicinais, subdivididas em 12 canteiros e espaço central, sendo cultivadas duas plantas medicinais em cada um deles. Cada uma dessas divisões é correspondente ao pico energético de um órgão do corpo humano, seguindo um ciclo, exceto o centro, em que está o tecido epitelial, sendo esta uma adaptação. Conclusão: A realização do projeto oportunizou o resgate e a valorização do uso de plantas medicinais entre professores, discentes e comunidade, contribuindo para o cuidado compartilhado e promovendo a saúde de todos.

Descritores: Terapias Complementares; Plantas Medicinais; Promoção da Saúde.

\section{ABSTRACT}

Objective: To report experience in the process of constructing and implementing a medicinal garden for the maintenance and health care of a community. Synthesis of data: This was an experience report from the development of a university extension project entitled "Learning Space - the medicinal clock of the human body" developed in the neighborhood of a municipality in

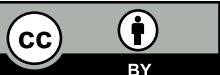


the central region of Rio Grande do Sul state, Brazil. Community members, professionals from the fields of Nursing, Biology, Agronomy, and Landscaping, Nursing students, high school students and scholarship students from a higher education institution took part in the project. The activities were conducted from April to December 2017 and 2018. The clock was developed in a public territory of the community, consisting of 26 medicinal plants subdivided into 12 flowerbeds and central space, and cultivated two medicinal plants in each of them. Each of these divisions corresponds to the energetic peak of an organ of the human body, following a cycle, except the center, which is the epithelial tissue, which is an adaptation. Conclusion: The achievement of the project provided the opportunity to rescue and value the use of medicinal plants among teachers, students, and the community, contributing to shared care and promoting the health of all.

Descriptors: Complementary Therapies; Plants, Medicinal; Health Promotion.

\section{RESUMEN}

Objetivo: Relatar la experiencia del proceso de construcción e implementación de un huerto medicinal para la manutención y el cuidado de la salud de una comunidad. Síntesis de los datos: Se trata de un relato de experiencia a partir del desarrollo de un proyecto de extensión universitaria intitulado "Espacio de aprendizaje - reloj medicinal del cuerpo humano" desarrollado en el barrio de un municipio de la región central del estado de Rio Grande do Sul, Brasil. Han participado del proyecto los integrantes de la comunidad, los profesionales de las áreas de Enfermería, Biología, Agronomía y Paisajismo, los académicos de enfermería, los estudiantes de educación secundaria y los becarios estudiantes de una institución de educación superior. Se realizaron las actividades en los meses entre abril de 2017 y diciembre de 2018. El reloj ha sido desarrollado en un territorio público de la comunidad formado por 26 plantas medicinales subdivididas en 12 canteros y espacio central donde se ha cultivado dos plantas medicinales en cada uno de ellos. Cada una de esas divisiones corresponde al punto máximo de energía de un órgano del cuerpo humano, siguiendo uno ciclo, excepto el centro en el cual está el tejido epitelial que es una adaptación. Conclusión: La realización del proyecto ha permitido el rescate y la valoración del uso de plantas medicinales entre los profesores, los discentes y la comunidad contribuyendo para el cuidado compartido y promocionando la salud para todos.

Descriptores: Terapias Complementarias; Plantas Medicinales; Promoción de la Salud.

\section{INTRODUÇÃO}

Os saberes e as práticas populares de cuidado, mesmo sendo, em alguns momentos, desvalorizados pela ciência e pelo sistema tradicional de saúde, continuam integrando a cultura das práticas de cuidado da população(1). A utilização das plantas medicinais para tratamento, cura e prevenção de doenças acompanha a evolução humana, constituindo os costumes, saberes e tradições de diferentes sociedades, ainda que seu uso esteja pautado no conhecimento empírico, difundido pelo saber popular entre as gerações ${ }^{(2,3)}$. Tal fato reforça a importância de estudos de etnobotânica para o resgate, registro e valorização desse tipo de conhecimento, evitando que sejam esquecidos ao longo dos tempos ${ }^{(4)}$.

Com o surgimento das Ciências Naturais e do método científico, no século XIX, as plantas medicinais passaram a interessar aos estudiosos, que visavam a comprovar a eficácia e segurança de sua utilização(5). Tal fato fez com que as plantas medicinais passassem a ser vistas como matéria-prima para a criação de novos fármacos, distanciando-as do uso empírico(6).

Após os anos 80, surgiram programas de fitoterapia na rede pública de saúde, a partir da criação da Resolução da Comissão Interministerial de Planejamento e Coordenação, de 1988, a qual regulamentou o uso de fitoterápicos nos serviços de saúde ${ }^{(7)}$. Dentre as motivações para a utilização da fitoterapia, estão: o aumento dos recursos terapêuticos, o resgate dos saberes populares, a preservação da biodiversidade, o fomento à agroecologia, o desenvolvimento social, além da educação ambiental, popular e permanente ${ }^{(8)}$.

A Resolução da Diretoria Colegiada da Agência Nacional de Vigilância Sanitária (RDC) n. ${ }^{\circ} 26$ define fitoterápico como o produto obtido a partir da matériaprima vegetal com a finalidade profilática, curativa e/ou paliativa. Nessa categoria estão incluídos os medicamentos fitoterápicos e os produtos tradicionais fitoterápicos, enquanto a planta medicinal é considerada a espécie vegetal, sendo utilizada com propósitos terapêuticos ${ }^{(9)}$.

O desenvolvimento dos programas de fitoterapia resultou em diversas ações advindas desde a construção de laboratórios de produção de fitoterápicos até a criação de hortos medicinais ${ }^{(10)}$. Entre as políticas públicas relacionadas às plantas medicinais e fitoterápicas, destaca-se o Decreto $n .{ }^{\circ} 5.813$, de 2006 , o qual instituiu a Política Nacional de Plantas Medicinais e Fitoterápicos, e a Portaria Interministerial n. ${ }^{\circ} 2960$, de 2008, sendo fundamentais para a introdução de plantas medicinais e fitoterápicos no Sistema Único de Saúde (SUS) ${ }^{(11)}$. 
Em 2006, foi instituída a Política Nacional de Práticas Integrativas e Complementares (PNPIC) no Sistema Único de Saúde (SUS), enfatizando a inserção das Práticas Integrativas e Complementares em Saúde (PICS) na Atenção Primária à Saúde (APS). Porém, apesar de as plantas medicinais figurarem entre as principais terapias utilizadas in natura ou manipuladas pelos brasileiros ${ }^{(12)}$, sua incorporação na rede pública de saúde se dá lentamente ${ }^{(12)}$.

Pode-se citar o estado do Ceará como berço das "farmácias vivas", pois conta com hortos de plantas medicinais, laboratórios de produção de fitoterápicos, atividades e manuais de orientação ofertados no SUS ${ }^{(1)}$, de acordo com a Lei Estadual n. ${ }^{\circ}$ 12.951, de 07 de outubro de 1999, que instituiu a Política Estadual de Implantação da Fitoterapia em Saúde Pública ${ }^{(13)}$.

Contudo estudos evidenciaram que, apesar do desenvolvimento, ampliação e difusão do tema no país, há uma precariedade no que tange ao processo de formação dos profissionais da saúde, visto que estudantes podem concluir a sua graduação sem ter contato com o estudo das plantas medicinais ${ }^{(14,15)}$. Desse modo, em relação a orientações quanto às plantas medicinais, estudos demonstram um déficit no conhecimento, evidenciado no processo formativo dos profissionais da saúde, constituindo um obstáculo para a atuação e implementação de atividades relacionadas ao uso de plantas medicinais nos serviços de saúde ${ }^{(8,16)}$.

O desconhecimento sobre a PNPIC ${ }^{(12)}$ é observado em estudos nacionais ${ }^{(8,12,16,17)}$ e alguns autores ${ }^{(18,19)}$ atribuem tal fato à pouca divulgação, ao ceticismo e ao fato de os profissionais ainda estarem propensos ao modelo biomédico, além do fato de esse assunto não ser abordado na academia, fomentando ainda mais esses padrões. Ao ignorar essa temática durante a formação do profissional da saúde, a implementação dessa política torna-se mais dificultosa, pois conhecer as PICS possibilitaria respaldar o uso dessas terapias e garantir segurança para o usuário e o prescritor ${ }^{(17,19)}$

Esses fatos reforçam a importância das instituições de ensino superior (IES) incluírem essa formação na grade curricular de cursos da área da saúde, principalmente dos cursos de Enfermagem e Medicina, uma vez que são os profissionais que mais prescrevem fitoterápicos ${ }^{(20,21)}$. Estudos revelam que esses profissionais não recebem instruções durante a graduação sobre fitoterapia e plantas medicinais, e que seus conhecimentos sobre fitoterapia são baseados, principalmente, na cultura popular ${ }^{(17,21)}$. Assim, o estudo dessa temática pode contribuir para o melhor relacionamento dos enfermeiros e pacientes, com vistas ao cuidado integral, pois estariam preparando, capacitando e motivando esses profissionais a indicar as plantas medicinais e fitoterápicos ${ }^{(22)}$.

Associando esse conhecimento com a fitoterapia, a medicina chinesa desenvolveu o Horto medicinal - relógio do corpo humano, que busca cultivar as plantas medicinais que se relacionam com os doze meridianos, facilitando sua identificação e associação aos órgãos e sistemas corporais(23).

A inserção do profissional de Enfermagem nesse meio é reconhecida pela Resolução n. ${ }^{\circ} 581 / 2018$, a qual dispõe sobre as especialidades do enfermeiro em diversas áreas, dentre elas: acupuntura, fitoterapia, homeopatia, ortomolecular, terapia floral, reflexologia podal, reiki, yoga, toque terapêutico, musicoterapia, cromoterapia e hipnose ${ }^{(24)}$. Com isso, pode-se citar a transversalidade da temática com a Política Nacional de Promoção da Saúde (PNPS ${ }^{(25)}$ e com o Programa de Fitoterápicos e Plantas Medicinais ${ }^{(10)}$, objetivando a promoção da saúde da comunidade.

Portanto, a temática é relevante, visto que pretende descrever a experiência de novas atividades de extensão e de pesquisa, voltadas ao compartilhamento de saberes com a população acerca do uso correto, do cultivo e do cuidado das plantas medicinais e da promoção da saúde através da elaboração de um relógio de horto medicinal integrado entre universidade e população. O presente relato justifica-se devido à criação de um espaço didático, de convivência e de compartilhamento de ideias, que teve como finalidade aproximar o saber acadêmico e o saber popular. Este estudo objetivou relatar a experiência no processo de construção e implementação de um horto medicinal em uma comunidade para a manutenção e cuidado à saúde.

\section{SÍNTESE DOS DADOS}

Relato de experiência originado da vivência de um projeto de extensão desenvolvido em um município do interior do Rio Grande do Sul, Brasil, em uma comunidade em situação de vulnerabilidade econômica e social, em concordância aos objetivos da PNPS ${ }^{(25)}$. As atividades foram realizadas entre os meses de abril a dezembro de 2017 e 2018. Além da comunidade local, participaram da atividade profissionais de Enfermagem, Biologia, Agronomia e Paisagismo, acadêmicos do curso de Enfermagem e estudantes do ensino médio. Destaca-se que o projeto envolveu dois bolsistas do Fundo de Incentivo à Extensão (FIEX) de uma IES.

O presente estudo originou-se de um projeto de extensão que está registrado no Portal de Projetos da Universidade Federal de Santa Maria (UFSM), Registro n. ${ }^{\circ}$ 047139, intitulado Espaço de aprendizagem - relógio medicinal do corpo humano(26). 
A aproximação da equipe de trabalho com a comunidade iniciou-se com atividades acadêmicas voltadas à prevenção da hipertensão arterial sistêmica (HAS), identificada durante aulas práticas na Unidade de Saúde de referência. Com isso, foi realizada uma oficina de produção do "sal de ervas", direcionada aos hipertensos e diabéticos, na qual os participantes eram estimulados a reduzir seu consumo de sal e de condimentos com sal a partir de atitudes simples, como retirar o saleiro da mesa, consumir temperos naturais e evitar alimentos industrializados ${ }^{277}$.

O sal de ervas consiste no incremento de ervas frescas, como orégano, alecrim, manjericão e salsinha, ao sal de cozinha, com vistas a reduzir a ingesta de sódio e ainda assim deixar os alimentos temperados e saborosos. Ressalta-se que o acréscimo de temperos naturais na alimentação constitui um dos dez passos para uma alimentação saudável para pessoas com HAS ${ }^{(28)}$. Ademais, as ervas aromáticas não apenas influenciam na redução do consumo de sódio, como também, possibilitam que o indivíduo se beneficie de suas propriedades terapêuticas ${ }^{(29)}$.

Durante o manuseio das ervas, os participantes revelaram fazer uso de plantas medicinais, sendo mencionado pela equipe de trabalho que, em alguns municípios, havia hortos medicinais comunitários, explicando o seu funcionamento e construção, bem como a sua importância para a comunidade em que estava inserido, mas que, infelizmente, não havia naquela região do município. Após a oficina, os usuários demonstraram interesse sobre a temática de plantas medicinais e o desejo de desenvolver a construção e a manutenção do relógio medicinal do corpo humano, o qual relaciona o uso das plantas medicinais à saúde humana.

Dessa forma, buscou-se fortalecer o vínculo e a articulação entre a IES e comunidade prosseguindo com as atividades multidisciplinares de educação, voltadas, principalmente, à promoção da saúde e à prevenção de doenças ${ }^{(25)}$, associado aos cuidados sistemáticos com o horto. Destaca-se que foram realizados encontros e reuniões com a comunidade para dialogar sobre a função de cada planta, seu manuseio, e consolidando a construção do Relógio medicinal do corpo humano ao sanar dúvidas da população para a sua utilização e manutenção. Posteriormente, propôs-se à população local um termo de compromisso, o qual aceitava a entrada da IES na comunidade, assumindo o compromisso e a parceria para a construção e manutenção do relógio, em um processo de corresponsabilização da comunidade e da instituição de ensino.

A comunidade participou de todas as etapas de planejamento e de construção do horto, sendo uma delas a escolha do local de implementação, que ocorreu a partir de reuniões da IES com a população, sendo definido um terreno público ao lado da igreja, de fácil acesso aos moradores, com as condições adequadas, como boa incidência da luz solar e solo fértil. Depois, realizou-se a demarcação e a medição dos canteiros, capinas, revolvimento e preparo da terra, além do cultivo das mudas de plantas medicinais que formaram o horto medicinal.

Foi realizada uma parceria com a Empresa de Assistência Técnica e Extensão Rural (EMATER), com o intuito de qualificar as atividades, tendo em vista a interdisciplinaridade e a complexidade do tema, associando o uso popular das plantas com os horários nos quais o corpo humano apresenta maior atividade, de acordo com a medicina tradicional chinesa $(\mathrm{MTC})^{(30)}$. Os materiais utilizados como ferramentas de trabalho foram: enxada, pá, baldes e outros. Para a divisão dos canteiros, utilizaram-se tijolos do tipo floreira, e os canteiros foram preenchidos com composto orgânico de propriedade dos moradores da comunidade, bem como adubo orgânico.

O horto é composto por 26 plantas medicinais, subdivididas em 12 canteiros e o espaço central, cada um com duas plantas medicinais. Cada divisão correspondeu ao pico energético de um órgão do corpo humano, que segue um ciclo(30), exceto o espaço central, que foi adequado com duas plantas do tecido epitelial. Destaca-se que estabeleceu-se a escolha dessas plantas a partir de três critérios: plantas reconhecidas pela RDC $n .^{\circ} 10 / 2010^{(31)}$, plantas que constassem na Relação nacional de plantas medicinais de interesse ao SUS (RENISUS) e plantas de uso comum entre os usuários, que podiam, ainda, ser alternadas, conforme a realização de estudos e pesquisas.

Ressalta-se a participação da comunidade durante todo o processo de construção e implementação do relógio medicinal, juntamente com os colaboradores. As responsabilidades de manutenção do horto são da IES e da comunidade, estando incluído os processos de replantio, irrigação e capinas, quando necessário, sendo as plantas fornecidas pela instituição de ensino e algumas pela própria comunidade.

\section{As plantas utilizadas, os órgãos vitais e a medicina tradicional chinesa}

Após a estruturação dos canteiros, iniciou-se a plantação das mudas, conforme orientação da medicina tradicional chinesa (MTC) ${ }^{(32)}$. Em cada canteiro, realizou-se a identificação das plantas por uma doutora em Botânica da UFSM, a fim de se evitar incidentes relacionados ao uso incorreto, no que se refere à semelhança entre espécies e denominação que a planta recebeu. Assim, foram colocadas placas contendo o nome popular e científico da planta, bem como a família a qual pertencia, de modo que cada planta ficasse individualizada. 
A utilização de plantas medicinais permite ao ser humano maior conectividade com o ambiente, acessando a natureza para ajudar o organismo a normalizar funções fisiológicas prejudicadas e podendo, ainda, auxiliar na restauração da imunidade enfraquecida, promovendo, consequentemente, a desintoxicação e o rejuvenescimento ${ }^{(32)}$.

AMTC, unida à teoria do relógio cósmico, aponta que o organismo humano tem um ciclo de circulação energética, no qual a energia vital passa pelo circuito de uma forma já determinada, obedecendo diariamente o mesmo ritmo ${ }^{(33)}$. A energia vital percorre o circuito dentro de um ritmo, num percurso de 24 horas, iniciando no meridiano do pulmão. Após a passagem dessa energia vital pelo fígado, volta ao pulmão e daí por diante ${ }^{(34)}$.

A MTC considera que cada órgão possui, pelo menos, uma planta correspondente com um horário de pico de ação ${ }^{(33)}$. Seus estudiosos ${ }^{(34)}$ dizem que as plantas malva e alcaçuz, marcela e anis/erva-doce, espinheira-santa e gengibre, alho e batata-yacon, erva-cidreira e embaúba, alcachofra e melissa, cavalinha e chapéu-de-couro, carqueja e quebra-pedra, erva-de-bicho e soja, camomila e mil-folhas, dente-de-leão e poejo, hortelã e picão, calêndula e alecrim, correspondem aos respectivos órgãos: pulmão, intestino grosso, estômago, baço e pâncreas, coração, intestino delgado, bexiga, rins, sistema circulatório, triplo aquecedor (sistema digestivo, respiratório e excretor), vesícula biliar, fígado e tecido epitelial (ao centro do horto, sendo uma adequação).

Dessa forma, em 24 horas, cada um dos 12 meridianos principais tem um período de duas horas no qual sua atividade atinge o pico máximo de funcionamento. Isto significa que, em um tratamento, o horário próprio do meridiano é o mais indicado para a sedação da energia, que terá como resultado restabelecer o órgão ou função( ${ }^{(33)}$.

Para a construção do relógio medicinal houve parcerias internas e externas a IES. Dentre as parcerias internas, houve a participação de dois enfermeiros doutores e docentes, responsáveis pelo projeto, de uma enfermeira vinculada ao Departamento de Enfermagem, de duas biólogas doutoras e docentes que auxiliaram na identificação das plantas, de um paisagista doutor e docente que cedeu tijolos e matéria orgânica, bem como de dois acadêmicos bolsistas da graduação em Enfermagem.

Dentre as parcerias externas à IES, pode-se citar um agrônomo da EMATER que auxiliou na doação das plantas para a construção do relógio medicinal. Cabe destacar a importância do envolvimento e comprometimento de toda a comunidade local na construção, bem como o envolvimento de dois estudantes bolsistas do ensino médio que nela residem. O intuito primordial do projeto pautou-se na promoção do resgate cultural do uso das plantas medicinais e do saber popular, com o estímulo para sua utilização, além de fortalecer o vínculo da academia com a comunidade local, que esteve presente em todo o processo de construção do relógio.

Os autores deste relato perceberam a relevância do trabalho interdisciplinar, tendo em vista ser um processo educacional mais completo e voltado ao mundo do trabalho. A utilização consciente das plantas medicinais só traz benefícios para o ser humano(35), portanto, cabe às IES propagarem seu uso, aperfeiçoando cientificamente o conhecimento popular, e é isto que se espera com o desenvolvimento deste projeto.

\section{O relógio medicinal do corpo humano e suas contribuições}

O projeto de extensão que resultou na construção do relógio medicinal oportunizou a convivência e o fortalecimento de vínculo entre comunidade, profissionais da saúde e outras áreas do conhecimento, discentes de graduação e estudantes do ensino médio. Além disso, destaca-se que a construção do relógio no território da comunidade possibilita a corresponsabilidade das pessoas que ali residem com o cuidado e manutenção de sua saúde, visto que o relógio medicinal do corpo humano se constituiu como uma oportunidade de promoção à saúde, conhecimento e aprofundamento em relação às plantas medicinais. Essas questões abarcam a Política Nacional de Promoção da Saúde em diversos aspectos, visto que, além da utilização de um espaço público, há a ampliação da autonomia dos sujeitos e o favorecimento da preservação do meio ambiente ${ }^{(25)}$.

Destaca-se que a visitação ao horto é aberta, pois se encontra em espaço público, no entanto apenas os moradores da vila utilizam as plantas. Além disso, realizaram-se visitas e atividades com a comunidade e as escolas do município. Quanto às atividades de extensão, foram desenvolvidas por bolsistas do curso de Enfermagem, os quais explicavam o relógio, o corpo humano, as plantas e suas contribuições, ou seja, a efetividade da planta e os horários de pico de ação, bem como organizavam o espaço junto com a comunidade para receber os visitantes.

Dentre os pontos positivos do projeto, estão: o incentivo ao uso das plantas medicinais pela comunidade e o engajamento da população local no processo de construção e implementação do horto, promovendo a saúde da comunidade $^{(25)}$. O relógio medicinal está disponivel para a população conhecer, aprender e utilizar ${ }^{(10)}$, fortalecendo o vínculo acadêmico com a população e contribuindo com o processo formativo dos estudantes de graduação.

Dentre as limitações, encontram-se a pouca aproximação da ESF com o projeto e a dificuldade de acesso até a comunidade, necessitando de transporte, o que limitou a participação de algumas escolas devido a dificuldades financeiras. 
Enquanto participantes deste processo, como docentes e discentes, percebeu-se a importância do projeto, pois a realização de cada etapa permitiu a apreensão de conhecimentos teóricos e práticos acerca da construção e implementação de um horto medicinal, com diferentes tipos de plantas, provendo subsídios para a reprodução das atividades em outras oportunidades, tanto da vida pessoal como profissional. Pesquisa realizada com grupos étnicos do Paquistão revelou que há interligação de diferentes conhecimentos no uso de plantas medicinais ${ }^{(36)}$.

Entende-se a relevância de ações de extensão como a apresentada no presente estudo, visto que existe uma lacuna no conhecimento, devido aos poucos estudos que abordam especificamente a temática ${ }^{(30,31,37)}$.

Assim, estimula-se o desenvolvimento de projetos similares nos mais variados cenários, desde serviços de saúde, escolas, creches, IES, comunidades e residências, visando a ampliar a utilização das plantas medicinais e disseminar esses saberes, promovendo qualidade de vida e saúde à população.

Esse resgate do conhecimento medicinal das plantas para os estudantes e comunidade, além de promover a integração universidade - comunidade, foi uma semente plantada com a finalidade de que esse conhecimento não se perca. Ao final da experiência, foi possível verificar que a utilização de plantas medicinais é aceita pela comunidade. Assim, a complementação do conhecimento popular e científico sobre a produção e o uso de plantas medicinais é fundamental para sua segurança e eficácia. A experiência permitiu, ainda, redescobrir a importância da fitoterapia no ensino, pesquisa e extensão, e as contribuições em potencial que ela pode fornecer para a ciência da Enfermagem, em especial no que concerne à promoção da saúde e à prevenção de doenças.

\section{CONCLUSÃO}

A construção do horto medicinal possibilitou o resgate e a valorização do uso das plantas medicinais, permitindo que a comunidade fosse orientada acerca do cultivo e da utilização das plantas cotidianamente. Ademais, o relógio do corpo humano e as plantas medicinais propiciaram o desenvolvimento de atividades de promoção à saúde e preservação do meio ambiente, além do reconhecimento do corpo humano, da identificação e da produção de plantas medicinais.

A atividade proporcionou a troca de saberes populares e científicos, a reflexão sobre a preservação da natureza, o reconhecimento da importância da biodiversidade da flora presente no sul brasileiro. Além disso, a implementação do horto fortaleceu o vínculo entre comunidade e academia, aproximando os participantes de conceitos básicos relacionados ao saber popular, à medicina popular, às plantas medicinais, à saúde e ao meio ambiente.

\section{AGRADECIMENTOS E CONFLITOS DE INTERESSE}

À Universidade Federal de Santa Maria que, por meio do Fundo de Incentivo à Extensão (FIEX), financiou o projeto.

Declaramos que o manuscrito não apresenta relações que possam implicar em potenciais conflitos de interesses.

\section{CONTRIBUIÇÕES}

Marcio Rossato Badke contribuiu com a elaboração e delineamento do estudo; a aquisição, análise e interpretação de dados; e a redação e/ou revisão do manuscrito. Daiana Cristina Wickert, Gabriela Oliveira, Jordana Lima da Silva e Hentielle Feksa Lima contribuíram com a aquisição, análise e interpretação de dados; e a redação e/ou revisão do manuscrito. Maria Denise Schimith, Laís Mara Caetano da Silva e Silvana Bastos Cogo contribuíram com a redação e/ou revisão do manuscrito.

\section{REFERÊNCIAS}

1. Ministério da Saúde (BR). Práticas integrativas e complementares: plantas medicinais e fitoterapia na Atenção Básica [Internet]. Brasília: Ministério da Saúde; 2012 [acesso em 2018 Set 12]. Disponível em: http:// bvsms.saude.gov.br/bvs/publicacoes/praticas_integrativas_complementares_plantas_medicinais_cab31.pdf

2. Badke MR, Somavilla CA, Heisler EV, Andrade A, Budó MLD, Garlet TMB. Saber popular: uso de plantas medicinais como forma terapêutica no cuidado à saúde. Rev Enferm UFSM [Internet]. 2016 [acesso em 2018 Abr 15];6(2):225-34. Disponível em: https://periodicos.ufsm.br/reufsm/article/view/17945/pdf_1

3. Oliveira RA, Silva RV, Neves VLD, Nascimento IO, Oliveira FS, Nunes SEA, et al. Perfil etnobotânico de plantas utilizadas como medicinais na comunidade de Bom Jesus, município de Imperatriz-MA. Rev Educ 
Ambient Ação [Internet]. 2018 [acesso em 2019 Mar 04];18(66). Disponível em: http://www.revistaea.org/ artigo.php?idartigo $=3531$

4. Messias MCTB, Menegatto MF, Prado ACC, Santos BR, Guimarães MFM. Uso popular de plantas medicinais e perfil socioeconômico dos usuários: um estudo em área urbana em Ouro Preto, MG, Brasil. Rev Bras Plantas Med [Internet]. 2015 [acesso em 2019 Mar 04];17(1):76-104. Disponível em: http://www.scielo.br/pdf/ rbpm/v17n1/1983-084X-rbpm-17-01-00076.pdf

5. Miranda CAC. A arte de curar nos tempos da colônia: limites e espaços da cura [Internet]. $3^{\mathrm{a}}$ ed. Recife: Editora Universitária da UFPE; 2017 [acesso em 2019 Set 25]. Disponível em: https://www.ufpe.br/ documents/39938/950195/E-book+A+ARTE+DE+CURAR.pdf/79de256e-161d-4fb1-bf4e-e802193f223a

6. Saad GA, Léda PHO, Sá IM, Seixlack ACC. Fitoterapia contemporânea: tradição e ciência na prática clínica [Internet]. $2^{\mathrm{a}}$ ed. Rio de Janeiro: Guanabara Koogan; 2018 [acesso em 2019 Mar 30]. Disponível em: https:// integrada.minhabiblioteca.com.br/\#/books/9788527730433/

7. Brasil. Ministério da Previdência e Assistência Social. Resolução CIPLAN nº 8, de 8 de março de 1988. Implantar a prática de Fitoterapia nos Serviços de Saúde, assim como orientar, através das Comissões Interinstitucionais de Saúde (CIS), buscarem a inclusão da Fitoterapia nas Ações Integradas de Saúde (AIS), e/ou programação do Sistema Unificado e Descentralizado de Saúde (SUDS), nas Unidades Federadas, visando colaborar com a prática oficial da medicina moderna, em caráter complementar [Internet]. Diário Oficial da União: seção 1, Brasília, DF, p. 3999-4000, 11 mar 1988 [acesso em 2019 Fev 04]. Disponível em: http://www.cremesp.org.br/library/modulos/legislacao/versao_impressao.php?id=6213

8. Ceolin S, Ceolin T, Casarin ST, Severo VO, Ribeiro MV, Lopes ACP. Plantas medicinais e sua aplicabilidade na atenção primária à saúde. Rev APS [Internet]. 2017 [acesso em 2019 Mar 03];20(1):81-8. Disponível em: http://ojs2.ufjf.emnuvens.com.br/aps/article/view/15812/8251

9. Ministério da Saúde (BR), Agência Nacional de Vigilância Sanitária. Resolução da Diretoria Colegiada RDC $n^{\circ} 26$, de 13 de maio de 2014. Dispõe sobre o registro de medicamentos fitoterápicos e o registro e a notificação de produtos tradicionais fitoterápicos [Internet]. 2014 [acesso em 2018 Set 12]. Disponível em: http://bvsms.saude.gov.br/bvs/saudelegis/anvisa/2014/rdc0026_13_05_2014.pdf

10. Ministério da Saúde (BR). Programa de Fitoterápico e Plantas Medicinais [Internet]. Brasília: Ministério da Saúde; 2015 [acesso em 2019 Set 28]. Disponível em: http://www.saude.gov.br/noticias/693-acoes-eprogramas/40041-programa-de-fitoterapico-e-plantas-medicinais

11. Ministério da Saúde (BR). Política e Programa Nacional de Plantas Medicinais e Fitoterápicos [Internet]. Brasília: Ministério da Saúde; 2016 [acesso em 2018 Abr 15]. Disponível em: http://bvsms.saude.gov.br/bvs/ publicacoes/politica_programa_nacional_plantas_medicinais_fitoterapicos.pdf

12. Ministério da Saúde (BR). Política Nacional de Práticas Integrativas e Complementares no SUS- PNPIC-SUS [Internet]. 2ª ed. Brasília: Ministério da Saúde; 2015 [acesso em 2019 Out 14]. Disponível em: https://bvsms. saude.gov.br/bvs/publicacoes/politica_nacional_praticas_integrativas_complementares_2ed.pdf

13. Ceará. Lei no 12.951, de 07.10.99. Dispõe sobre a Política de Implantação da Fitoterapia em Saúde Pública no Estado do Ceará [Internet]. Diário Oficial do Estado do Ceará, 07 de outubro de 1999 [acesso em 2019 Abr 14]. Disponível em: file:///C:/Users/731088835/Downloads/LEIZNZ12.951ZZZ1999.pdf

14. Palma JS, Badke MR, Heisler EV, Heck RM, Meincke MK. Modelos explicativos do setor profissional em relação às plantas medicinais. Rev Pesqui (Univ Fed Estado Rio J) [Internet]. 2015 [acesso em 2018 Dez 10];7(3):2998-3008. Disponível em: http://www.redalyc.org/pdf/5057/505750947026.pdf

15. Ceolin T, Ceolin S, Heck RM, Noguez PT, Souza ADZ. Relato de experiência do curso de plantas medicinais para profissionais de saúde. Rev Baiana Saúde Pública [Internet]. 2013 [acesso em 2018 Nov 20];37(2):50111. Disponível em: http://files.bvs.br/upload/S/0100-0233/2013/v37n2/a4457.pdf

16. Souza ADZ, Heinen HM, Amestoy SC, Mendieta MC, Piriz MA, Heck RM. O Processo de trabalho dos enfermeiros da atenção primária e a Política Nacional de Plantas Medicinais/Fitoterápicos. Rev Bras Plantas Med [Internet]. 2016 [acesso em 2019 Mar 03];18(2):480-7. Disponível em: http://www.scielo.br/pdf/rbpm/ v18n2/1516-0572-rbpm-18-2-0480.pdf

17. Mattos G, Camargo A, Sousa CAD, Zeni ALB. Plantas medicinais e fitoterápicos na Atenção Primária 
em Saúde: percepção dos profissionais. Ciênc Saúde Colet [Internet]. 2018 [acesso em 2019 Set 19];23(11):3735-44. Disponível em: http://www.scielo.br/pdf/csc/v23n11/1413-8123-csc-23-11-3735.pdf

18. Ischkanian PC, Pelicioni MCF. Desafios das práticas integrativas e complementares no SUS visando a promoção da saúde. Rev Bras Crescimento Desenvolv Hum [Internet]. 2012 [acesso em 2019 Set 28];22(2):233-8. Disponível em: http://pepsic.bvsalud.org/pdf/rbcdh/v22n2/pt_16.pdf

19. Varela DSS, Azevedo DM. Saberes e práticas fitoterápicas de médicos na estratégia saúde da família. Trab Educ Saúde [Internet]. 2014 [acesso em 2019 Set 28];12(2):273-90. Disponível em: http://www.scielo.br/pdf/ tes/v12n2/a04v12n2.pdf

20. Caccia-Bava MCGG, Bertoni BW, Pereira AMS, Martinez EZ. Disponibilidade de medicamentos fitoterápicos e plantas medicinais nas unidades de atenção básica do Estado de São Paulo: resultados do Programa Nacional de Melhoria do Acesso e da Qualidade da Atenção Básica (PMAQ). Ciênc Saúde Colet [Internet]. 2017 [acesso em 2019 Set 28];22(5):1651-9. Disponível em: http://www.scielo.br/pdf/csc/v22n5/1413-8123csc-22-05-1651.pdf

21. Nascimento BJ Jr, Tínel LO, Silva ES, Rodrigues LA, Freitas TON, Nunes XP, et al. Avaliação do conhecimento e percepção dos profissionais da estratégia de saúde da família sobre o uso de plantas medicinais e fitoterapia em Petrolina-PE, Brasil. Rev Bras Plantas Med [Internet]. 2016 [acesso em 2019 Set 28];18(1):57-66. Disponível em: http://www.scielo.br/pdf/rbpm/v18n1/1516-0572-rbpm-18-1-0057.pdf

22. Nunes JD, Maciel MV. A importância da informação do profissional de enfermagem sobre o cuidado no uso das plantas medicinais: uma revisão de literatura. Rev Fitos [Internet]. 2017 [acesso em 2019 Set 28];10(4):518-25. Disponível em: http://revistafitos.far.fiocruz.br/index.php/revista-fitos/article/view/385/pdf

23. Pereira MCL. Horto medicinal: relógio do corpo humano como ferramenta pedagógica de aprendizagem intranscultural [caderno temático] [Internet]. Curitiba: Secretaria de Educação do Estado do Paraná; 2014 [acesso em 2019 Out 20]. Disponível em: http://www.diaadiaeducacao.pr.gov.br/portals/cadernospde/ pdebusca/producoes_pde/2014/2014_utfpr_dtec_pdp_maria_cristina_laus_pereira.pdf

24. Conselho Federal de Enfermagem. Resolução COFEN no 581, de 11 julho de 2018. Atualiza, no âmbito do Sistema COFEn/Conselhos Regionais de Enfermagem, os procedimentos para registro de títulos de pósgraduação lato e stricto sensu concedido a enfermeiros e lista as especialidades. Diário Oficial da União: seção 1, Brasília, DF, p. 119-, 11 jul. 2018.

25. Ministério da Saúde (BR). Política Nacional de Promoção da Saúde. $3^{\mathrm{a}}$ ed. Brasília: Ministério da Saúde; 2010.

26. Universidade Federal de Santa Maria. Espaço de aprendizagem: relógio medicinal do corpo humano [Internet]. Santa Maria: UFSM; 2019 [acesso em 2019 Mar 03]. Disponível em: https://portal.ufsm.br/projetos/ publico/projetos/view.html?idProjeto=58367

27. Sociedade Brasileira de Cardiologia. Diretriz Brasileira de Hipertensão. Rio de Janeiro: SBC; 2017.

28. Ministério da Saúde (BR), Secretaria de Atenção à Saúde, Departamento de Atenção Básica. Estratégias para o cuidado da pessoa com doença crônica: hipertensão arterial sistêmica [Internet]. Brasília: Ministério da Saúde; 2013 [acesso em 2019 Out 15]. Disponível em: http://bvsms.saude.gov.br/bvs/publicacoes/ hipertensao_arterial_sistemica_cab37.pdf

29. Graça APSR, Camolas J, Gregório MJ, Sousa S, Andrade C, Santos G. Programa Nacional para a Promoção da Alimentação Saudável: 2017 [Internet]. Portugal: Direção-Geral da Saúde; 2019 [acesso em 2019 Out 15]. Disponível em: https://www.alimentacaosaudavel.dgs.pt/activeapp/wp-content/files_mf/1446660770Ervasaro m\%C3\%A1ticasUmestrat\%C3\%A9giaparaaredu\%C3\%A7\%C3\%A3odosalnaalimenta\%C3\%A7\%C3\%A3odos Portugueses.pdf

30. Heisler EV, Budó MLD, Schimith MD, Perottoni J, Heisler ED. Origem do saber popular no cultivo de horto medicinal. Rev Enferm UFSM [Internet]. 2018 [acesso em 2019 Mar 03];8(1):33-47. Disponível em: https:// periodicos.ufsm.br/reufsm/article/view/27086/pdf

31. Brasil. Ministério da Saúde. Resolução - RDC n 10, de 09 de março de 2010 [Internet]. Dispõe sobre a notificação de drogas vegetais junto à Agência Nacional de Vigilância Sanitária (ANVISA) e dá outras 
providências. [2010] [acesso em 2018 Dez 04]. Disponível em: http://189.28.128.100/dab/docs/legislacao/ resolucao10_09_03_10.pdf

32. Lucas SD, Gonçalves AGB, Kosinski J, Salomoni SE, Andreolla N. A utilização das plantas medicinais do relógio biológico do corpo humano [Internet]. In: Sistema Integrado de Ensino, Pesquisa e Extensão; 2018; Cachoeira do Sul. Cachoeira do Sul: Siepex; 2018 [acesso em 2019 Fev 26]. Disponível em: https://www. doity.com.br/anais/8-siepex/trabalho/63039

33. Velloso CC, Wermann AM, Fusiger TB. Horto medicinal: relógio do Corpo Humano [Internet]. Putinga: EMATER; 2005 [acesso em 2019 Fev 22]. Disponível em: http://www.biodiversidade.rs.gov.br/ arquivos/1159290630estudo_caso_HORTO_MEDICINAL_RELOGIO_DO_CORPO_HUMANO.pdf

34. Campos MK, organizador. Relógio Medicinal do Corpo Humano [Internet]. Florianópolis: BU Publicações/ UFSC; 2018 [acesso em 2019 Mar 03]. Disponível em: https://repositorio.ufsc.br/handle/123456789/191696

35. Badke MR, Lautenschleger G. Adequação do uso de plantas medicinais ao relógio biológico humano. In: Freitas VL, Badke MR. Práticas Integrativas e Complementares do SUS: O [re]conhecimento de técnicas milenares no cuidado à saúde contemporânea. Curitiba: Nova Práxis Editorial; 2019. p. 119-40.

36. Salim MA, Ranjitkar S, Hart R, Khan T, Ali S, Kiran C, et al. Regional trade of medicinal plants has facilitated the retention of traditional knowledge: case study in Gilgit-Baltistan Pakistan. J Ethnobiol Ethnomed [Internet]. 2019 [acesso em 2019 Mar 03];15(1):6. Disponível em: https://ethnobiomed.biomedcentral.com/ articles/10.1186/s13002-018-0281-0

37. Poswal FS, Russell G, Mackonochie M, MacLennan E, Adukwu EC, Rolfe V. Herbal teas and their health benefits: a scoping review. Plant Foods Hum Nutr [Internet]. 2019 [acesso em 2019 Mar 03];74(3):266-76. Disponível em: https://link.springer.com/article/10.1007\%2Fs11130-019-00750-w

\section{Endereço para correspondência:}

Marcio Rossato Badke

Universidade Federal de Santa Maria - UFSM

Av. Roraima, 1000 / Cidade Universitária

Bairro: Camobi

CEP: $97105-900$ - Santa Maria - RS - Brasil

E-mail: marciobadke@gmail.com

Como citar: Badke MR, Wickert DC, Oliveira G, Silva JL, Lima HF, Schimith MD, et al. Construção e implementação de um horto medicinal: um projeto de extensão universitária. Rev Bras Promoç Saúde. 2019;32:9384. 